\title{
REVIEW
}

\section{Best practice in primary care pathology: review 2}

\section{W S Smellie, J O Forth, C A M McNulty, L Hirschowitz, D Lilic, R Gosling, D Bareford, E Logan, K G Kerr, G P Spickett, J Hoffman, A Galloway, C A Bloxham}

J Clin Pathol 2006;59:113-120. doi: 10.1136/jcp.2005.031526

This second best practice review examines five series of common primary care questions in laboratory medicine: (1) laboratory testing for allergy, (2) diagnosis and monitoring of menopause, (3) the use of urine cytology, (4) the usefulness of the erythrocyte sedimentation rate, and (5) the investigation of possible urinary tract infection. The review is presented in a question-answer format. The recommendations represent a précis of guidance found using a standardised literature search of national and international guidance notes, consensus statements, health policy documents, and evidence based medicine reviews, supplemented by MEDLINE EMBASE searches to identify relevant primary research documents. They are standards but form a guide to be set in the clinical context. Most are consensus rather than evidence based. They will be updated periodically to take account of new information.

See end of article for authors' affiliations

\section{Correspondence to:} Dr W S A Smellie, Department of Chemical Pathology, Bishop Auckland 'General Hospital, Cockton Hill Road, Bishop Auckland, County Durham DL14 6AD, UK; info@smellie. com

Accepted for publication 2 August 2005
$\mathrm{T}$ his is the second in a planned series of reviews to answer several questions that arise in primary care use of pathology. The methodology for obtaining the questions, searching the literature, and writing the answers has been described in this journal.

Each subject is introduced with a brief summary of the type of information found and is handled separately.

Although the individual subjects are not related because they cover the disciplines of clinical biochemistry, microbiology, immunology, haematology, and cellular pathology, they are designed once completed to form a resource that will be indexed and cover a wide range of the most common primary care laboratory issues, to be made available to users.

Where the new General Medical Services (GMS) contracts in the UK make specific reference to a laboratory test, the indicator or target is appended at the end of the answer.

\section{IGE (TOTAL AND ALLERGEN SPECIFIC) MEASUREMENT (DL AND GPS)}

This short question series examines the use of total and allergen specific IgE, mostly in the context of the investigation of allergy. The documents found provide fairly close consensus and several comment on the need to identify the appropriate situations for their use. There appears to be increasingly limited need for the measurement of total IgE, particularly in the investigation of allergy.
When should I request total IgE in general practice?

We recommend that there is very limited need for this test in general practice, except as an adjunct to the diagnoses listed below.

- IgE concentrations can be increased in nonallergic states such as parasite infections, Churg-Strauss vasculitis, certain immune deficiencies such as the hyper-IgE syndrome, IgE myeloma, Hodgkin lymphoma, and atopic dermatitis. $^{2}$ These are all rare conditions, usually diagnosed in secondary care, and the measurement of IgE is not crucial to the diagnosis.

- Total IgE alone can neither confirm nor exclude allergy: increased concentrations may suggest an atopic state, but normal or low values do not exclude allergy. ${ }^{3}$ Normal or low IgE concentrations also cannot be used as a prescreening test for radioallergosorbent testing (RAST). ${ }^{45}$ Therefore, it is inappropriate to request total $\operatorname{IgE}$ in isolation from general practice in this context.

GMS contract indicator: none.

When should I request allergen specific IgE (RAST)?

We recommend allergen specific IgE measurement in the presence of the clinical suspicion of type 1 IgE mediated hypersensitivity/allergy, principally for inhaled antigens. There is no need to request total IgE when requesting RAST.

- Seasonal rhinoconjunctivitis (hay fever).

- Perennial rhinoconjunctivitis.

- Anaphylaxis.

- Acute urticaria with angio-oedema.

- Food allergy (with suspected trigger).

- Drug allergy (with suspected trigger).

- Suspected allergy to insect stings.

There is limited consensus guidance on the use of RAST testing in particular, as distinct from allergy testing in general, and the guidance above is drawn principally from review articles and by extrapolation from clinical studies.

Abbreviations: AUA, American Urological Association; FSH, follicle stimulating hormone; GMS, General Medical Services; MH, microscopic haematuria; RAST, radioallergosorbent testing; UTI, urinary tract infection 
RAST refers to one of the first tests used to test allergen specific IgE, which is no longer in use; a more appropriate name is allergen specific IgE testing. It is used as a more accessible or more convenient alternative to skin prick testing. ${ }^{6}$ It is only useful for assessing type I IgE mediated reactions (immediate hypersensitivity); RAST tests are therefore not useful for assessing pseudo-allergic reactions that are not mediated by IgE (such as non-allergic food intolerance; reactions to radiocontrast media, morphine, and aspirin; physical urticarias, etc.). ${ }^{58}$ Angio-oedema without urticaria is usually not an IgE mediated allergic reaction. ${ }^{9}$ RAST testing and skin prick testing are of little value in chronic urticaria, which is usually not caused by IgE dependent mechanisms.

RAST tests must be requested for a specified antigen based on clinical history. ${ }^{5-9}$ They are of no benefit as screening tests without specified antigens. ${ }^{7-9}$ It follows from this that requests should not be for widespread antigen screening. Test results must be interpreted in conjunction with clinical findings. ${ }^{25}{ }^{7-9}$ The specificity and sensitivity of RAST results vary for the different allergens tested (for example, poor for fruits and vegetables). Overall, RAST tests have relatively low sensitivity and can be negative in the presence of allergy. ${ }^{3}{ }^{10-12}$ In addition, adverse reactions to foods are IgE mediated allergies in only about a third of patients. ${ }^{511} 12$ Therefore, RAST tests are of limited value in this situation. It follows from this that RAST testing in food intolerance is unlikely to be helpful, and we recommend that it is used only in the initial investigation of severe acute food intolerance reactions where a specific food is suspected.

The efficacy of unconventional/alternative allergy testing has not been confirmed, and can neither substitute nor complement RAST and other classic allergy tests. ${ }^{78}$ Therefore, these tests are not recommended.

GMS contract indicator: none.

\section{INVESTIGATION OF THE MENOPAUSE (RG AND WSAS)}

The documents found are consistent in their recommendations for laboratory testing in the menopause. The clearest message from these documents is that hormone measurements have no role in diagnosing menopause in patients of menopausal age with typical symptoms, or in monitoring patients on oral hormone replacement. They identify specific areas for their use. These answers do not specifically address premature ovarian failure, which will be examined in later questions on subfertility.

\section{When should I request tests for menopause?}

We recommend that hormone assays are of no value in investigating women over 45 years old with typical menopausal symptoms. Follicle stimulating hormone (FSH) assays in suspected premature ovarian failure or an atypical menopausal presentation are limited to indicating that ovarian failure may have occurred.

It is agreed that a serum FSH result in excess of 30-40 IU/ litre, depending on author and testing laboratory, is the best single biochemical indicator for ovarian failure in the menopause. ${ }^{13-16}$ However, in the climacteric phase identification of the menopause in a woman by FSH assay is not recommended because hormone values fluctuate greatly during this period. Therefore, the diagnosis of menopause in patients over 45 years who have menopausal symptoms should be based solely on clinical criteria. ${ }^{14}$ 17-19
In younger women presenting with possible early menopause $(<45$ years) or premature ovarian failure $(<40$ years $)$ FSH assays can be useful. The finding of two separate FSH results of $>40 \mathrm{IU} /$ litre taken four to eight weeks apart suggests ovarian failure. ${ }^{18}$ One guideline recommends testing oestrogen and FSH. ${ }^{13}$ However, premenopausal results cannot exclude ovarian failure as a diagnosis, ${ }^{18}$ and although fertility declines greatly in association with FSH values over 25 IU/ litre, they offer no guarantee of infertility, and advice to discontinue contraception is based on the length of amenorrhoea (see below). Population ranges of FSH even 10 years after clinical onset of menopause are also ${ }^{20}$ extremely wide, and can depend on assay method. ${ }^{18}$ Hormone tests are also thought to play no role in deciding on the type of hormone replacement therapy for symptomatic menopause if being considered..$^{18}$

Two other patient groups who may benefit from FSH assays are those on the oral contraceptive and those who have had a hysterectomy. In both cases, the biological marker of oligomennorhoea as an indicator of ovarian failure is not applicable. In women coming off oral contraception, alternative contraception should be used for one year of amenorrhoea in those $>50$ years old and for two years in those $<50$ years old. ${ }^{13} 1418$

There is considerable unnecessary requesting of FSH assays in women over 45 years with menopausal symptoms. This could be greatly reduced by the use of requesting guidelines agreed between the laboratory and requesting clinicians. ${ }^{21}$

GMS contract indicator: none.

What tests are required to monitor women on hormone replacement therapy?

We do not recommend that FSH or oestrogen should be measured to monitor patients on hormone replacement therapy except in the following situations:

- Questionable absorption.

- Before replacement of oestrogen implants.

- Questionable compliance.

Women should be assessed only on clinical response where treatment is given for symptomatic relief and treatment altered where appropriate..$^{13}{ }^{22-25}$ The assay of oestrogen may occasionally be of value to establish its adequate absorption in women where poor absorption is suspected. Measurements have also been recommended in women with an oestrogen implant before implant replacement to ensure that no accumulation of oestrogen has occurred to avoid supraphysiological concentrations and possible tachyphylaxis. ${ }^{14} 2324$ Neither FSH nor oestrogen measurement is recommended in women receiving oral hormone replacement, ${ }^{14}$ because results are difficult to interpret meaningfully, and vary depending on oestrogen type. There is a theoretical case for measuring oestradiol in patients with persisting symptoms if poor treatment compliance is suspected.

GMS contract indicator: none.

\section{ERYTHROCYTE SEDIMENTATION RATE (EL AND DB)}

The erythrocyte sedimentation rate (ESR), often used as a non-specific screen for illness, causes interpretation difficulties because of various factors that influence values and can lead to further investigations. This question examines situations when use of the test is and is not recommended, based on a range of guidelines and primary studies of test utility. It does not attempt to compare its usefulness with 
that of plasma viscosity, which is used as an alternative test in many situations.

\section{When should I request an ESR?}

\section{We recommend that ${ }^{26}$ ESR should be used:}

- To evaluate patients with unexplained symptoms or a deterioration of health status when:

(a) inflammatory, neoplastic, or infectious disease is suspected and

(b) a specific diagnosis is not made effectively by other means.

- To monitor the activity of giant cell arteritis, polymyalgia rheumatica, and inflammatory arthritis.

There is no evidence to support the use of the ESR in asymptomatic individuals and this test should not be appended to "routine" investigations. ${ }^{27} 28$

The ESR is a relatively non-specific test that is frequently ordered during the diagnosis and monitoring of disease. A variety of factors influence the sedimentation rate. ${ }^{27} 29$ Disease related factors that may affect the ESR include plasma immunoglobulin and fibrinogen concentrations, and the presence and degree of anaemia. Factors unrelated to disease processes that may affect ESR values include age, sex, and drug treatment.

A simple rule for calculating the normal ESR with age is: $($ age +10$) \div 2$ for women, age $\div 2$ for men. ${ }^{30}$

There is no evidence to support the use of the ESR in asymptomatic individuals. ${ }^{27}{ }^{29}$ Raised ESR values are found in a variety of pathological states. If the clinical history and physical findings are suggestive of specific disease processes, other investigations are usually more appropriate. ${ }^{28}$ For instance, although individuals with an ESR greater than $100 \mathrm{~mm}$ /hour are probably suffering from serious systemic disease, the presence of such diseases (malignancy, infection, cirrhosis, collagen disease, etc.) is generally detectable by clinical examination and history. However, the ESR may provide useful information when:

- Used as a diagnostic criterion for temporal arteritis and polymyalgia rheumatica. ${ }^{28} 3132$

- Monitoring response to treatment in temporal arteritis and polymyalgia rheumatica. ${ }^{31}{ }^{33}$ A clinical response would be expected in two to four days but inflammatory markers normalise over two weeks or longer. ${ }^{34}$

- Used as a component of some clinical indices of rheumatoid arthritis. ${ }^{35}$

- Following the course of patients with rheumatoid arthritis or other connective tissue disorders. ${ }^{36}$

- Screening for tissue infection in specific situations-for example, after orthopaedic surgery or suspected pelvic inflammatory disease ${ }^{37}$-although $\mathrm{C}$ reactive protein may be more useful in diagnosis and monitoring response. ${ }^{39} 40$

- Assessing response of Hodgkin disease to treatment. ${ }^{41} 42$

- Assessing elderly persons with vague complaints in whom there is a moderate to strong possibility of underlying disease, but no definite findings after history and physical examination. $^{43} 44$
For those general practices who are served by a laboratory that offers plasma viscosity as a test in preference to ESR.

\section{When should I measure plasma viscosity?}

Done under ideal conditions, changes in the ESR and plasma viscosity roughly parallel one another in many but not all situations. Both reflect changes in fibrinogen and/or globulin concentrations. The measurement of viscosity has several advantages. Unlike the ESR, which may be falsely raised as a result of the vagaries of ambient room temperature, age, anaemia, or length of time after specimen collection, plasma viscosity is very reproducible, and is thought to reflect more closely the clinical severity and the efficiency of treatment of a given disease state. In addition, in contrast to the ESR, the normal range is the same for both sexes and for all ages above 3 years. ${ }^{45}$ A more detailed comparison of ESR and plasma viscosity will follow in a later question answer set.

GMS contract indicator: none.

\section{URINE CYTOLOGY (LH, JH, AND CAB)}

In a laboratory setting, most requests for urine cytology are received from hospital clinics, with primary care specimens forming a minority. The guidance provided is taken mostly from studies of test utility rather than consensus guidance, and relates specifically to the initial primary care investigation of the situation described.

When should I request urine cytology (particularly in the context of microscopic haematuria; $\mathrm{MH}$ )?

We recommend urine cytology in patients in the following situations:

- Patients with symptomatic MH.

- Asymptomatic MH in patients $>40$ years old or younger patients with risk factors for urological cancer.

- The follow up of patients who have been treated for bladder cancer (in conjunction with urinalysis for MH and other tests if available).

- As a secondary investigation in frank haematuria.

Gross or visible haematuria requires evaluation of the upper and lower urinary tract. ${ }^{46-48}$ Urine cytology has a supportive role in the evaluation of these patients ${ }^{49}$ in conjunction with upper tract imaging, cystoscopy, and bladder biopsy. However, in one study, ${ }^{49}$ urine cytology did not lead to the discovery of additional tumours that were not detected by other investigations. Recent urinary tract instrumentation should be excluded as a cause of gross haematuria. ${ }^{48}$

MH (by dipstick analysis) is more controversial. Although it is generally accepted that symptomatic $\mathrm{MH}$ requires microscopy, this has recently been questioned. ${ }^{50}$ There are no reliable data on the incidence of underlying bladder neoplasms in patients with symptomatic MH. Nonetheless, one small study of women who had incontinence and/or irritative voiding and $\mathrm{MH}$ showed cytology to be of value,, and the American Urological Association (AUA) best practice guidance recommends urine cytology in patients with a history of irritative voiding symptoms. ${ }^{52}$ Urine cytology is not helpful in the evaluation of men with lower urinary tract 
symptoms ${ }^{47}$ because asymptomatic $\mathrm{MH}$ is a frequent finding in patients who have benign prostatic hyperplasia, ${ }^{53}$ and urine cytology is not an investigation of choice to detect prostatic malignancy. It has not been evaluated in this context.

Urinary tract infection (UTI) does not require investigation with urine cytology, but by microbiological testing. ${ }^{5-57}$ Cytological samples in the setting of UTI may be obscured by polymorphs, and it is sensible to exclude and treat infection before submitting samples for cytological evaluation if indicated in a patient presenting with a UTI.

Asymptomatic $\mathrm{MH}$ is common in adult primary care populations $(2.5-4.3 \%),{ }^{58}$ and up to $11 \%$ of patients with asymptomatic $\mathrm{MH}$ have been reported to have underlying urothelial malignancy ${ }^{59-61}$ However, in a review of 17 series, comprising a total of 5000 patients, urological cancer was diagnosed in $<3 \%$ of cases. A Californian study found asymptomatic $\mathrm{MH}$ in $2.9 \%$ of 20751 patients, $0.5 \%$ of whom had urothelial cancer, yet cancer was also found in $0.5 \%$ without MH. Therefore, the authors concluded that the presence of asymptomatic $\mathrm{MH}$ was not significantly associated with urological cancer or other serious urological disease. $^{62}$ No studies have demonstrated improved outcomes from screening for asymptomatic $\mathrm{MH}^{6}{ }^{63}$

Screening for asymptomatic MH cannot be recommended as a means of detecting urological malignancy, but in patients $>40$ years with an incidental finding of $\mathrm{MH}$, the AUA recommends complete urological evaluation (including cytology). ${ }^{52}$ The importance of age as a risk factor is supported by a study in a subspecialised urological setting where $87 \%$ of patients in whose samples malignant cells were found were $>50$ years of age. However, it should be noted that $72 \%$ had a history of gross haematuria. The $\mathrm{AUA}^{52}$ also recommends complete urological evaluation (including cytology) in younger patients with a history that is "suspicious of underlying urological disease". The relative merits of full urological investigation (including cytology) in younger patients with asymptomatic MH have not been evaluated and are therefore debatable. ${ }^{64} 65$

A combination of $\mathrm{MH}$ and proteinuria in younger patients is a predictor of non-neoplastic primary renal disease. ${ }^{66}$ In patients with this combination of findings on dipstick examination, the cytological identification of red blood cell casts and dysmorphic red blood cells may serve as a further indicator of renal parenchymal disease. ${ }^{61}$ However, there appear to be differences in laboratory practice as to whether this identifier would form part of microbiology macroscopy/ culture examination or whether urine cytology would be expected, because the conventional role of urine cytology is to diagnose malignancy. Primary care organisations should clarify current arrangements in place in their laboratory.

Cytology is advised in patients with risk factors for transitional cell carcinoma, ${ }^{67}$ although other screening methods ${ }^{66}{ }^{67}$ probably have higher combinations of sensitivity and specificity in patients with low grade non-invasive tumours and those with carcinoma in situ. ${ }^{67} 68$ In patients with incidental $\mathrm{MH}$, the risk factors listed by the AUA as indications for urine cytology include: smoking history, occupational exposure to carcinogenic chemicals or dyes (benzenes or aromatic amines), analgesic abuse (for example, phenacetin), cyclophosphamide, and pelvic irradiation. ${ }^{52}$ Known schistosomiasis bladder infection may reasonably be included in relevant populations as a predisposing factor for bladder cancer. ${ }^{69}$ Cytology has been used in the follow up of patients who have been treated for bladder cancer in conjunction with testing for $\mathrm{MH}$.

In the laboratory a single cytospin deposit $^{70}$ (as opposed to the preparation of duplicate slides) is adequate for cytological evaluation, saves resources, and caused minimal loss of clinically relevant information.

GMS contract indicator: none.

\section{MANAGING URINARY SYMPTOMS (CAMM, AG, AND KGK)}

These questions and answers make recommendations about when and how primary care should investigate urinary symptoms. This guidance is based on evidence discussed in detail in Health Protection Agency (www.hpa.org.uk) and PRODIGY (www.prodigy.nhs.uk) guidelines and in the other key references quoted.

When should I send a urine specimen in patients with possible urinary tract infection?

In adults we recommend a urine specimen in:

- Failed antibiotic treatment or persistent symptoms in all individuals. ${ }^{71}$

- Recurrent UTI. ${ }^{11}$

- Suspected pyelonephritis. ${ }^{72}$

- All men with urinary symptoms consistent with infection. $^{73}$

- Catheterised patients with fever $\geqslant 38^{\circ} \mathrm{C}$, rigors, vomiting, new onset confusion, or costovertebral tenderness ( see "In catheterised patients" below) ${ }^{74}$

- Pregnancy $^{75}{ }^{76}$ :

- screening for asymptomatic bacteriuria at first antenatal visit

- investigation of urinary symptoms.

- Anatomical abnormalities of the genitourinary tract. $^{73}$

- Renal impairment. $^{73}$

- Suspected or known immunosuppression-for example, chemotherapy.

- In sexually active men and women with urinary symptoms consider Chlamydia trachomatis infection and send appropriate specimens.

Waiting for the results of urine culture in patients with suspected UTI delays diagnosis and is not cost effective. Conversely, prescribing antibiotics to all patients with urinary symptoms will lead to overuse of antibiotics. Empirical antibiotic treatment in acute, uncomplicated UTI in women ${ }^{77}$ should be based on the severity and classic nature of the symptoms and urine dipstick results, with the exception of the specific situations listed in the recommendations above. Submission of a urine specimen before starting treatment may be helpful to identify antibiotic susceptibility, particularly in the event of treatment failure, although it should not delay treatment. ${ }^{78}$

Patients with failed antibiotic treatment or recurrent UTI are more likely to have an infection caused by a bacterium that is resistant to antibiotics. ${ }^{71}$ Therefore, urine culture and susceptibility is used to confirm that antibiotic choice is appropriate.

Patients with renal impairment or abnormalities of the genitourinary tract are more likely to have ascending infection/pyelonephritis and antibiotic resistant bacteria, and it is therefore most important to confirm antibiotic susceptibility. ${ }^{73}$ Similarly, bacteraemia is much more common in patients with pyelonephritis or fever than in 
uncomplicated UTI (15-20\%) and, therefore, it is important to confirm antibiotic susceptibility ${ }^{73}$ in these cases.

In children we recommend a urine specimen from:

- Neonates or infants with:

- unexplained fever $>24$ hours

- irritability

- prolonged neonatal jaundice

- failure to thrive.

- Children of any age with:

- unexplained fever

- urinary symptoms

- vomiting, unexplained abdominal pain, loin pain

- haematuria, hypertension

- suspected sexual abuse.

Guidance is based on recommendations of the Royal College of Physicians for the management of acute UTI in children. ${ }^{79}$

Greater opportunities for health gain lie in improving the detection and treatment of acute UTI in children than in the detection and management of vesico-ureteric reflux. ${ }^{79}$ Increased submission of urine samples from children with the above signs or symptoms leads to greater detection of UTI. ${ }^{80}$ Fever alone can produce pyuria in children, ${ }^{81}$ highlighting the need for laboratory diagnosis of infection.

In the elderly we recommend a urine specimen if:

- Dysuria (burning or pain passing urine).

- Fever $\geqslant 38^{\circ} \mathrm{C}$.

- Acute change in continence.

Or:

- Fever plus one of, new or worsening:

- urgency

- frequency

- suprapubic pain

- urinary incontinence

- gross haematuria.

Do not send urine from elderly patients if:

- Asymptomatic, irrespective of dipstick nitrite/leucocyte results.

- Subacute or chronic non-specific decline in health status as the only symptom because this is a nonspecific sign.

- Chronic incontinence without other symptoms.

- Catheterised and asymptomatic patients.

Asymptomatic bacteriuria is extremely common ${ }^{82}(20 \%$ of $>65$ year olds and $50 \%$ of $>80$ year olds or patients with dementia) and is not associated with increased morbidity. $^{82}$

Routine dipstick testing of urine samples for nitrite and leucocytes, and urine culture results in unnecessary antibiotics and treatment of asymptomatic bacteriuria. ${ }^{83} 84$
In catheterised patients ${ }^{7485}$ we recommend a urine specimen if:

- Fever or rigors without identified cause.

- New onset delirium or costovertebral tenderness.

- Pre-urological surgery.

Bacteriuria is present in most patients with longterm urinary catheters ( $>28$ days), but the incidence of fever in longterm catheterised patients is low (approximately one episode/100 days of catheterisation). In $50 \%$ of catheterised patients with fever, bacteraemia is present and is caused by ascending urinary infection. ${ }^{85}$ In patients with paraplegia, other non-specific symptoms, such as vomiting and increased spasticty, may indicate urinary tract infection.

Antibiotic treatment of asymptomatic bacteriuria in the presence of a catheter does not improve outcome.

When should I use urine dipsticks?

We recommend:

- Suspected uncomplicated UTI in adults in combination with assessment of clinical symptoms.

- Suspected UTI in children, to confirm suspicions of UTI, but a urine specimen should be submitted irrespective of results.

- Dipsticks are not reliable in young children (under 2 years).

- Dipstick results should always be interpreted in the context of clinical symptoms.

Testing for leucocytes (leucocyte esterase) and bacteria (nitrite) in combination appears at present to be the best means of dipstick testing.

Positive blood or leucocytes alone can be found in UTI but are also found in the urethral syndrome (urethral inflammation), ${ }^{86}$ which does not warrant antibiotic treatment. Nitrite testing alone is not recommended. ${ }^{87}$

A negative nitrite and leucocyte test can often be used to rule out UTI, because it has a reported negative predictive values of up to $95 \%$ or above, ${ }^{78}$ although reported metaanalysis sensitivity figures are lower $(80-90 \%) .^{88} 89$ These differences probably relate to clinical context. A positive result does not necessarily indicate infection: reported specificity is $60-80 \% .^{78} 88-90$

Several guidance sources ${ }^{789791}$ state that subsequent culture in uncomplicated lower UTI in women is not necessary, but stress the need for culture in the other situations listed above. The European Confederation of Laboratory Medicine guidelines recommend a "clinical filter" after the dipstick test is performed, to put the result in the clinical context before decision making. ${ }^{87}$ No robust simple algorithms combining symptom scores and dipstick results are available, ${ }^{92}$ and there is no clear consensus as to whether urine testing of any form is necessary in all women with possible UTI, in view of the usual self limiting course of the disease. ${ }^{93}$

When reading the dipstick test it is important to wait for the time recommended by the manufacturer. Nitrite is produced by the action of bacterial nitrate reductase in urine. Because contact time between bacteria and urine is needed, morning specimens are most reliable. ${ }^{94}$ It should also be noted that falsely negative results can be obtained with bacteria that cannot reduce nitrate, such as enterococci. Proteinuria occurs in UTI but is also present in other 


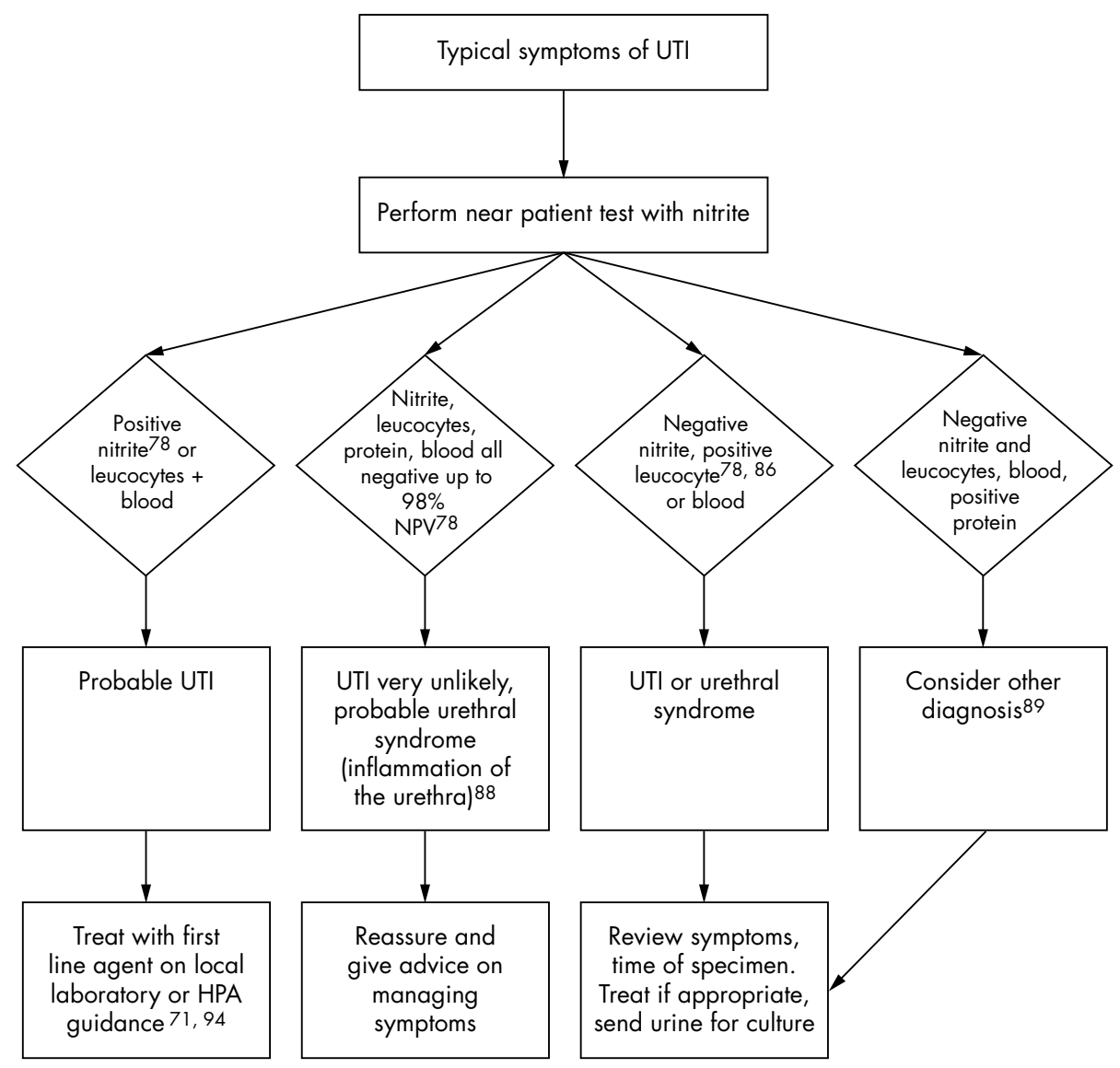

Figure 1 Guidance on how to interpret urine dipstick results. HPA, Health Protection Agency; NPV, negative predictive value; UTI, urinary tract infection.

conditions and is relatively non-specific. Other diagnoses should be considered for isolated proteinuria. ${ }^{95}$

\section{How should I interpret urine dipstick results? ${ }^{91}$}

Figure 1 provides a guideline flowchart of the interpretation of urine dipstick results.

\section{How should I obtain a urine specimen?}

We recommend:

- A midstream specimen should be obtained from men, women, and older children. In females, cleaning with water or antiseptic or holding the labia apart does not reduce contamination. ${ }^{96-99}$

- In toddlers, a potty washed in hot water with washing up liquid is better than a bag urine. ${ }^{100} \mathrm{~A}$ urine collection pad in a nappy may be used for infants. ${ }^{101}$

- Refrigerate specimens to prevent bacterial overgrowth, or use specimen pots containing boric acid. ${ }^{102}{ }^{103}$ Because boric acid is antibacterial, specimen pots should be filled to the indicated level to obtain the optimum boric acid concentration.

How should I interpret laboratory results?

\section{We recommend:}

- More than $10^{5}$ organisms $/ \mathrm{ml}$ (or $>10^{8}$ /litre) of pure growth (single bacterium isolated) obtained from a midstream specimen of urine has historically been considered diagnostic of UTI.

- However, lower counts of pure growth $\left(10^{3} / \mathrm{ml}\right.$ or less), or a mixed growth of two organisms only $\left(>10^{5} / \mathrm{ml}\right)$ may also indicate UTI in patients with signs and symptoms of UTI. ${ }^{87}$

Mixed growth from a midstream urine sample usually indicates that the urine has been contaminated on collection by perineal flora; this is often indicated by the presence of epithelial cells on the microscopy report. However, patients with longterm indwelling catheters may have infections with mixed organisms, although is should be emphasised that mixed growth from a cultured specimen of urine does not require antimicrobials in the absence of signs/symptoms of infection.

\section{ACKNOWLEDGEMENTS}

We are most grateful to Mrs S Richardson for typing this manuscript and to the following people who are kindly reviewing the group's work and adding valuable comments in addition to those of the steering group: Professor IS Young (Association of Clinical Biochemists); Dr R Gama and Dr R Herriot (Association of Clinical Pathologists); Dr AJ Mifsud (Association of Medical Microbiologists): Dr MJ Galloway (British Society for Haematology); Dr R Neal and Dr P Hannaford (Royal College of General Practitioners); Dr AB Provan (Royal College of Pathologists); and the other senior officers of these Associations and Colleges who assisted in recruiting reviewers. 
This work has been supported (in alphabetical order) by the Association of Clinical Biochemists, Association of Clinical Pathologists, Association of Medical Microbiologists, British Society for Haematology, Royal College of General Practitioners, Royal College of Pathologists, and the Sowerby Centre for Health Informatics in Newcastle, representatives of which have contributed to the reviewing process. The opinions stated are however those of the authors.

\section{Authors' affiliations}

W S A Smellie, C A Bloxham, J Hoffman, Bishop Auckland General Hospital, Cockton Hill Road, Bishop Auckland, County Durham DL14 6AD, UK

J O Forth, Prodigy, Sowerby Centre for Health Informatics, Bede House, All Saints Business Céntre, Newcastle Upon Tyre NEI 2ES, UK

C A M McNulty, Health Protection Agency Primary, Care Unit, Microbiology Department, Gloucester Royal Hospital, Great Western Road, Gloucester GLI 3NN, UK

L Hirschowitz, Department of Cellular Pathology, Royal United Hospital, Combe Park, Bath BA1 3NG, UK

D Lilic, University Hospital of North Durham, North Road, Durham DH1 5TW, UK

R Gosling, Darlington Memorial Hospital, Hollyhurst Road, Darlington, County Durham DL3 6HX, UK

D Bareford, Russells Hall Hospital, Dudley, West Midlands DY1 2HQ, UK

E Logan, Department of Haematology, Kings Mill Centre, Mansfield Road, Sutton in Ashfield, Nottingham NG17 4JL, UK

K G Kerr, Department of Microbiology, Harrogate District Hospital, Lancaster Park Road, Harrogate, North Yorkshire HG2 7SX, UK G P Spickett, Royal Victoria Infirmary, Queen Victoria Road, Newcastle upon Tyne NEI 4LP, UK

A Galloway, Royal Victoria Infirmary, Newcastle upon Tyne NE1 4LP, UK

\section{REFERENCES}

1 Smellie WSA, Wilson D, Finnegan DI, et al. Best practice in pathology. Methodology for constructing guidance. J Clin Pathol 2005;58:249-53.

2 Sicherer SH. Manifestations of food allergy: evaluation and management [review]. Am Fam Physician 1999:59:415-24, 429-30.

3 Saarinen UM, Juntunen $K$, Kajosaari $M$, et al. Serum lgE in atopic and nonatopic children aged 6 months to 5 years. A follow-up study. Acta Paediatr Scand 1982;71:489-94.

4 Overview of allergic diseases: diagnosis, management and barriers to care. The Allergy Report. 2004 American Academy for Allergy, Asthma and Immunology. http://www.theallergyreport.org/ (last accessed 4 November 2005).

5 Report of the IUIS/WHO working group. Use and abuse of 8 widely used diagnostic procedures in clinical immunology: a WHO memorandum. Clin Exp Immunol 1981;46:662-74.

6 Good Allergy Practice. Standards of care for providers and purchasers of allergy services within the NHS, 1994. Report by the RCP and RCPath. London: Royal College of Physicians and Royal College of Pathologists, 1994

7 Allergy. Conventional and alternative concepts, A report of the RCP Committee of Clinical Immunology and Allergy. London: The Royal College of Physicians, 1992

8 Allergy the unmet need. A blueprint for better patient care. London: Royal College of Physicians, 2003.

9 Guidelines for the study of adverse reactions to food. Position statement approved by the American College of Allergy and Immunology Board of Regents. Ann Allergy 1991;67:299-300.

10 Li JT. Allergy testing. Am Fam Physician 2002;66:621-5.

11 National Asthma Education and Prevention Program. Guidelines for the diagnosis and management of asthma: expert panel report 2, NIH publication no.98-4051. Bethesda: NIH, 1997:43-45.

12 Volcheck GW. Which diagnostic tests for common allergies? Postgrad Med 2001;109:71-9.

13 Institute of Clinical Systems improvement health care guideline. Menopause and hormone therapy : collaborative decision-making and management. October 2003. http://www.icsi.org/knowledge/ detail.asp? catlD = 29\&itemID = 172 (last accessed 14 February 2005), (HT).

14 The Canadian Consensus Conference on Menopause and Osteoporosis 2002 Update. J Obstet Gynaecol Can 2002;108:4-16.

15 The North American Menopause Society. Menopause core curriculum study guide, 2nd ed.http://www.menopause.org/edumaterials/studyguide/ studyguide.htm (last accessed 1 October 2004).

16 AACE medical guidelines for clinical practice for management of menopause. Endocr Pract 1999:51:353-366.

17 Groeneveld FPMJ, Biil D, Smulders M, et al. The Dutch College of General Practitioners (NHG) practice guideline "The menopause". September 2001.
http://www.nhg.artsennet.nl/upload/104/guidelined2/E73.htm (date accessed 21 June 2004)

18 Gow SM, Turner EL, Glasier A. The clinical biochemistry of the menopause and hormone replacement therapy. Ann Clin Biochem 1994;3:509-28.

19 Bastian LA, Smith CM, Nanda K. Is this woman perimenopausal? JAMA 2003;289:895-902.

20 Bijl D, Eijkelenburg-Waterreus JJH, De Jong HM, et al. NHG-standard amenorroea (NHG practice guideline "Amenorrhoea"). In: Thomas S, Geijer RMM, Van der Laan JR, et al. NHG-Standaarden voor de huisarts deel II [NHG Practice Guidelines for the general practitioner part II]. Utrecht: Bunge, 1996:54-64

21 Lapworth R, Anslow T, Clawson T. Audit of FSH requesting can alter long term practice. Journal of Clinical Excellence 2002;4:17-21.

22 Haines CJ, Fan S, Tang GWK, et al. Guidelines for the administration of hormone replacement therapy. The Hong Kong College of Obstetricians and Gynaecologists. Hong Kong Med J 1999;5:195-9.

23 L'Hermite M. Risks of estrogens and progestagens. Maturitas 1990;12:215-46.

24 Gangar K, Cust M, Whitehead Ml. Symptoms of oestrogen deficiency associated with supraphysiological plasma estradiol concentrations in women with estrodiol implants. BMJ 1989;299:601-2.

25 Alberta Medical Association. Laboratory endocrine testing guidelines: amenorrhea (without hirsuitism) and menopause. http:// www.topalbertadoctors.org/guidelines/fulltext/amenorrhea.pdf (last accessed 10 October 2004).

26 Green CJ, Wai SM, Anderson GM, et al. The erythrocyte sedimentation rate: an examination of the evidence. Vancouver (BC): $\mathrm{BC}$ Office of Health Technology Assessment; 1993, Report 92, 4D.

27 Brigden $M$. The erythrocyte sedimentation rate. Still a helpful test when used judiciously. Postgrad Med 1998;103:257-74.

28 Sox HC Jr, Liang MH. The erythrocyte sedimentation rate. Guidelines for rational use. Ann Intern Med 1986;104:515-23.

29 Bedell SE, Bush BT. Erythrocyte sedimentation rate. From folklore to facts. Am J Med 1985;78:1001-9.

30 Miller A, Green M, Robinson D. Simple rule for calculating normal erythrocyte sedimentation rate. BMJ 1983:286:266.

31 Kyle V, Cawston TE, Hazleman BL. Erythrocyte sedimentation rate and Creactive protein in the assessment of polymyalgia rheumatica/giant cell arteritis on presentation and during follow up. Ann Rheum Dis 1989:48:667-71.

32 Cantini F, Salvarani C, Olivieri I, et al. Erythrocyte sedimentation rate and Creactive protein in the evaluation of disease activity and severity in polymyalgia rheumatica: a prospective follow up study. Semin Arthritis Rheum 2000;30:17-24

33 Kyle V, Hazleman BL. The clinical and laboratory course of polymyalgia rheumatica/giant cell arteritis after the first two months of treatment. Ann Rheum Dis 1993;52:847-50.

34 Wolfe F. Comparative usefulness of C-reactive protein and erythrocyte sedimentation rate in patients with rheumatoid arthritis. J Rheumatol 1997:241477-85.

35 Li C, Dasgupta B. Corticosteroids in polymyalgia rheumatica-a review of different treatment schedules. Clin Exp Rheumatol 2000; 18(suppl 20):S56-7.

36 Ward MM. Relative sensitivity to change of the erythrocyte sedimentation rate and serum $\mathrm{C}$-reactive protein concentration in rheumatoid arthritis. I Rheumatol 2004;31884-95.

37 Spangehl MJ, Masri BA, O'Connell JX, et al. Prospective analysis of preoperative and intraoperative investigations for the diagnosis of infection at the sites of two hundred and two revision total hip arthroplasties. J Bone Joint Surg Am 1999:81:672-83.

38 Miettinen AK, Heinonen PK, Laippala P, et al. Test performance of erythrocyte sedimentation rate and $\mathrm{C}$-reactive protein in assessing the severity of acute pelvic inflammatory disease. Am J Obstet Gynecol 1993:5:1143-9.

39 Reliic M, Gorisek B. C-reactive protein and the treatment of pelvic inflammatory disease. Int J Gynaecol Obstet 1998;60:143-50.

40 Unkila-Kallio L, Kallio MJ, Eskola J, et al. Serum C-reactive protein, erythrocyte sedimentation rate, and white blood cell count in acute hematogenous osteomyelitis of children. Pediatrics 1994:93:59-62.

41 Friedman S, Henry-Amar M, Cosset JM, et al. Therapeutic implications and sites of relapse predicted by elevated post-therapy erythrocyte sedimentation rate in early stage Hodgkin disease. Am J Hematol 1991;37:253-7.

42 Henry-Amar M, Friedman S, Hayat M, et al. Erythrocyte sedimentation rate predicts early relapse and survival in early-stage Hodgkin disease. The EORTC lymphoma cooperative group. Ann Intern Med 1991;114:361-5.

43 Smith EM, Samadian S. Use of the erythrocyte sedimentation rate in the elderly. Br J Hosp Med 1994:51:394-7.

44 Tinetti ME, Schmidt A, Baum J. Use of the erythrocyte sedimentation rate in chronically ill, elderly patients with a decline in health status. Am J Med 1986;80:844-8

45 Dacie JV. Practical haematology, 6th ed. Edinburgh: Churchill Livingstone, 1984

46 Yun EJ, Meng MV, Carroll PR. Evaluation of patients with haematuria. Med Clin North Am 2004;88:329-43.

47 Malmström PU. Time to abandon testing for microscopic haematuria in adults? BMJ 2003;326:813-15.

48 Shah J. The investigation and management of haematuria-a continuing dilemma. Urooncology 2003;3:73-80.

49 Chahal R, Gogoi NK, Sundaram SK. Is it necessary to perform urine cytology in screening patients with haematuria? Eur Urol 2001;39:283-6.

50 Bove P, Kaplan D, Dalrymple N, et al. Re-examining the value of haematuria testing in patients with acute flank pain. J Urol 1999;162:685-7. 
51 Duldulao KE, Diokno AC, Mitchell B. Value of urinary cytology in women presenting with urge incontinence and/or irritative voiding symptoms. J Urol 1997; 157:113-16.

52 Grossfeld GD, Litwin MS, Wolf JS, et al. Evaluation of asymptomatic microscopic hematuria in adults: the American Urological Association best practice policy-part I: definition, detection, prevalence and etiology. Urology 2001;57:559-603

53 Ezz el Din K, Koch WF, de Wildt MJ, et al. The predictive value of microscopic haematuria in patients with lower urinary tract symptoms and benign prostatic hyperplasia. Eur Urol 1996;30:409-13.

54 Lammers RL, Gibson S, Kovacs D, et al. Comparison of test characteristics of urine dipstick analysis and urinalysis at various test cutoff points. Ann Emerg Med $2001 ; 38: 505-12$

55 Sultana RV, Zalstein S, Cameron P, et al. Dipstick urinalysis and the accuracy of clinical diagnosis of urinary tract infection. J Emerg Med 2001;20:13-19.

56 Moore KN, Murray S, Malone-Lee L, et al. Rapid urinalysis assays for the diagnosis of urinary tract infection. Br J Nurs 2001;10:995-1001.

57 D'Souza Z, D'Souza D. Urinary tract infection during pregnancy-dipstick urinalysis vs culture and sensitivity. J Obstet Gynaecol 2004;24:22-4.

58 Kryszczuk K, Kelsberg G. Should we screen adults for asymptomatic microhaematuria? J Fam Pract 2004;53:150-5.

59 Froom P, Froom J, Ribak J. Asymptomatic microscopic haematuria-is investigation necessary? J Clin Epidemiol 1997:50:1197-200.

60 Mansson A, Anderson H, Colleen S. Time lag to diagnosis of bladder cancer-influence of psychosocial parameters and level of health-care provision. Scand J Urol Nephrol 1993;27:363-9.

61 Fracchia JA, Motta J, Miller LS, et al. Evaluation of asymptomatic microhematuria. Urology 1995:46:484-9.

62 Hiatt RA, Ordenez JD. Dipstick urinalysis screening, asymptomatic microhematuria, and subsequent urological cancers in a population based sample. Cancer Epidemiol Biomarkers Prev 1994;3:439-43.

63 Messing EM, Young TB, Hunt VB, et al. Comparison of bladder cancer outcome in men undergoing haematuria home screening versus those with standard clinical presentations. Urology 1995;45:387-96.

64 Nabi G, Greene DR, O'Donnell M. How important is urinary cytology in the diagnosis of urological malignancies? Eur Urol 2003:43:632-6.

65 Sultana SR, Goodman CM, Byrne DJ, et al. Microscopic haematuria: urological investigation using a standard protocol. Br J Urol 1996;78:691-6.

66 Topham PS, Jethwa A, Watkins $M$, et al. The value of urine screening in a young adult population. Fam Pract 2004;21:18-21.

67 Hofland CA, Mariani AJ. Is cytology required for a haematuria evaluation? $J$ Urol 2004;171:324-6.

68 Ramakumar S, Bhuiyan J, Bess JA, et al. Comparison of screening methods in the detection of bladder cancer. J Urol 1999;161:388-94.

69 World Health Organisation. Cancer prevention. http, //www.who.int/ cancer/prevention/en (last accessed 19 May 2005).

70 Burton JL, Goepel JR, Lee JA. Demand management in urine cytology: a single cytospin slide is sufficient. J Clin Pathol 2000;53:718-19.

71 Stamm WE. Urinary tract infections and pyelonephritis. In: Harrison's principles of internal medicine, 14th ed. New York: McGraw-Hill, 2000.

72 Steinke DT, Seaton RA, Phillips G, et al. Factors associated with trimethoprim-resistant bacteria isolated from urine samples. J Antimicrob Chemother 1999;43:841-3.

73 Stamm WE, Hooton TM. Managing urinary tract infections in adults. N Engl J Med 1993;328:1328-34.

74 Warren JW. Catheter-associated urinary tract infections. Int J Antimicrob Agents 2001;17:229-303.

75 Cunningham FG, Lucas MJ. Urinary tract infections complicating pregnancy. Baillieres Clin Obstet Gynaecol 1994:8:353-73.

76 Urinary tract infection. MeReC Bulletin 1995;6:29-32.

77 Fenwick E, Briggs A, Hawke C. Management of urinary tract infection in general practice: a cost-effectiveness analysis. $\mathrm{Br} J \mathrm{Gen}$ Pract 2000:50:612-13.

78 Graham JC, Galloway A. The laboratory diagnosis of urinary tract infection. J Clin Pathol 2001;54:911-19.
79 Royal College of Physicians Report of a Working Group of the Research Unit Guidelines for the management of acute urinary tract infection in childhood. $J$ R Coll Physicians Lond 1991;25:36-42.

80 McNulty CAM, Bowen J, Clark G, et al. How should general practitioners investigate suspected urinary tract infection? Variations in laboratoryconfirmed bacteriuria in South West England. Comm Dis Public Health 2004;7:220-6.

81 Turner GM, Coulthard MG. Fever can cause pyuria in children. BMJ 1995;311:924.

82 Abrutyn E, Mossey J, Berlin JA, et al. Does asymptomatic bacteriuria predict mortality and does antimicrobial treatment reduce mortality in elderly ambulatory women? Ann Intern Med 1994; 120:827-33.

83 Rajagopalan S, Rho JP, Yoshikawa TT. An approach to antimicrobia therapy. In: Yoshikawa T, Ouslander JG, eds. Infection management for geriatrics in long-term care facilities. New York, USA: Marcel Dekker Inc 2002:155-71

84 McMurdo ME, Gillespie ND. Urinary tract infection in old age: overdiagnosed and over-treated. Age Ageing 2000;29:297-8.

85 Tambyah PA, Maki DG. Catheter-associated urinary tract infection is rarely symptomatic: a prospective study of 1497 catheterised patients. Arch Intern Med 2000; 160:678-82

86 Brumfitt W, Hamilton-Miller JM, Gillespie WA. The mysterious urethral syndrome [editorial]. BMJ 1991;303:1-2.

87 European Confederation of Laboratory Medicine (ECLM). European urinalysis group. European analysis guidelines. Scand J Clin Lab Invest 2000;60: 1-96.

88 Hurlbut TA III, Littenberg B, and the Diagnostic Technology Assessment Consortium. The diagnostic accuracy of rapid dipstick tests to predict urinary tract infection. Am J Clin Pathol 1991;96:582-8.

89 Pezzlo M. Detection of urinary tract infections by rapid methods. Clin Microbiol Rev 1988; 1:268-80

90 Jones C, Bennitt W, Halloran SP. Evaluation of urine reagent strips, Medical Devices Directorate Evaluation Report. London: HMSO, 1998.

91 Health Protection Agency. Diagnosis of urinary tract infection-quick reference guide, http://www.hpa.org.uk/infections/topics_az/ primary_care_guidance/uti_guide_290404.rff (last accessed 08 March 2005).

92 Bent S, Nallamouthu B, Simel D, et al. Does this woman have an acute uncomplicated urinary tract infection? JAMA 2002;287:2701-10.

93 Kolmos H, Little P. Should general practitioners perform diagnostic tests on patients before prescribing antibiotics? BMJ 1999;318:799-802

94 Czerwinski AW, Wilkerson RG, Merrill JA, et al. Further evaluation of the Griess test to detect significant bacteriuria. Part II. Am J Obstet Gynecol $1971 ; 110: 677-81$.

95 Scottish Intercollegiate Guidelines Network (SIGN) guidelines on investigation of asymptomatic proteinuria (No. 18) and microscopic haematuria (No. 17) (http://www.sign.ac.uk).

96 Hooton TM, Stamm WE. Diagnosis and treatment of uncomplicated UTI. Infect Dis Clin North Am 1997;11:551-81.

97 Roberts AP, Robinson IE, Beard KW. Some of the factors affecting bacterial colony counts in urinary infection. BMJ 1967;1:400-3.

98 Baerheim A, Digranes A, Hunskaar S. Evaluation of urine sampling technique: bacterial contamination of samples from women students. Br J Gen Pract 1992;42:241-43.

99 Lifshitz WE Kramer L. Outpatient urine culture. Arch Intern Med 2000; 150:2537-40

100 Rees JC, Vernon S, Pedler SJ, et al. Collection of urine from washed-up potties. Lancet 1996;348:197.

101 Lynster LCT, Nayar DM, Pedler SJ, et al. Home collection of urine for culture from infants by three methods. Survey of parents' preferences and bacterial contamination rates. BMJ 2000;320:1312-13.

102 Gillespie T, Fewster J, Masterton RG. The effect of specimen processing delay on borate urine preservation. J Clin Pathol 1999;52:95-9.

103 Porter IA, Brodie J. Boric acid preservation of urine samples. BMJ 1969;ii:353-5. 